Article

\title{
Social Capital Deviation in Capital Assistance System: Socio-Economic Studies of Coastal Communities
}

\author{
Mochamad Ridwan ${ }^{1, *}$ and Akhsanul In'am ${ }^{2}$ \\ 1 Economic Development Department, Faculty of Economic and Business, University of Bengkulu, \\ Jl. W.R. Supratman Kandang Limun, Bengkulu 38122, Indonesia \\ 2 Mathematics Education Department, Teacher Training and Education Faculty, University of Muhammadiyah \\ Malang, Jl. Raya Tlogomas No. 246, Malang 65144, Indonesia; akhsanul@umm.ac.id \\ * Correspondence: mridwan@unib.ac.id
}

check for updates

Citation: Ridwan, Mochamad, and Akhsanul In'am. 2021. Social Capital Deviation in Capital Assistance System: Socio-Economic Studies of Coastal Communities. Economies 9: 204. https://doi.org/10.3390/ economies 9040204

Academic Editor: Andreia Dionísio

Received: 10 August 2021

Accepted: 8 December 2021

Published: 20 December 2021

Publisher's Note: MDPI stays neutral with regard to jurisdictional claims in published maps and institutional affiliations.

Copyright: (c) 2021 by the authors. Licensee MDPI, Basel, Switzerland. This article is an open access article distributed under the terms and conditions of the Creative Commons Attribution (CC BY) license (https:// creativecommons.org/licenses/by/ $4.0 /)$.

\begin{abstract}
Revealing the practice of the capital assistance system in coastal communities that are indicated to have deviated from the principles of social capital, and building an integrated model as a solution for improving fishermen's low performance are the main objectives of this study. For this purpose, fishermen communities were chosen as the research sample. The research locations were focused on two provinces in Indonesia (Bengkulu and East Java provinces). Data were collected through observation, interview, and documentation methods. Discriminant and SEM/SmartPLS analysis methods were used to analyze quantitative data, while the descriptive analysis method was used to analyze qualitative data. The results show that the implementation of the capital assistance system by well-off fishermen (as capital providers) was proven to deviate from the principles of social capital because it was detrimental to small-scale/traditional fishermen. Six factors cause deviations in the capital assistance system: (a) the lack of "altruism cooperation" between well-off fisherman and small-scale/traditional fishermen; (b) mutual trust is not developed; (c) the powerlessness of the fishing community, which desperately needs funds for working capital; (d) government control is not effective; (e) the role of cooperative institutions (fisheries) as providers of funds/loan capital is still weak; and (f) an empowerment integrated model is considered capable of providing a comprehensive solution.
\end{abstract}

Keywords: capital assistance system; social capital; performance; fishermen; marine natural resources

\section{Introduction}

Poverty in fishing communities is a form of poverty with a relatively high level of severity compared to other communities. The severe condition of poverty in fishermen communities and its occurrence is inherent with behaviors that tend to be negative (moral hazard), such as illegal fishing practices and providing capital assistance that is detrimental and becomes a poverty trap for fishermen communities (Anna et al. 2019). This poverty trap presumably occurs due to various forms of vulnerability or powerlessness inherent in the fishing community itself, such as low capital, relatively low education, fish auction markets that do not function properly, etc. Substantially, this poverty trap focuses on the problem of the capital assistance system, which is burdensome, binding, and detrimental to small-scale fishermen (Nissa et al. 2019; Amir Zal et al. 2020). Due to these weaknesses, the providers of capital assistance (generally large groups of fishermen) may build a capital assistance system which in its initial phase appears to be very helpful to small-scale fishermen in terms of working capital, but eventually turns into a system which is not profitable and is detrimental, especially for small-scale fishermen (Siegelman et al. 2019; Malherbe et al. 2020).

In an economic development approach, fishermen's poverty can occur due to systemic, localistic processes, and can be due to powerlessness or other cultural and structural causes. In essence, poverty is a form of trap which is not visible and its mechanism tends to move 
in a circular manner and is cumulative, in which poverty will become deeper and worse. It is corroborated by several previous research results that the poverty trap can occur due to cultural factors or creating a culture of poverty. The culture of poverty that occurs in fishing communities is generally shown through slum housing conditions, irregular lifestyles, etc. This poverty, especially among small-scale fishermen, is a form of absolute poverty and cultural poverty, both of which occur simultaneously. Absolute poverty which occurs in fishing communities is closely related to the poverty line in that specific area. For example, the poverty line of a fishing community in one village in Bengkulu Province, Indonesia, is IDR 369,367 per capita/month. This poverty line of fishing communities is often associated with an index of the depth and severity of poverty. Several previous research results indicate that the poverty of fishermen in Indonesia tends to be a result of the indifference of the small-scale fishing communities to their condition, or it can be stated that poverty has turned into a culture in which fishermen feel comfortable with their conditions. A policy for breaking the chain of poverty will not work effectively if it does not involve the fishing community as one of the important elements of the coastal community, acting as a strategic local power or as the spearhead. The management or utilization of marine natural resources involving local workforces is not only focused on fishermen's own human resources, but also involves resources originating from the fishermen's family environment, such as from fishermen's wives (Azis et al. 2017; Hakim 2019; Wantini et al. 2020).

The poverty in fishing communities, especially among small-scale fishermen, can actually be seen in terms of "absolute poverty", "relative poverty", and "cultural poverty", all three of which can occur simultaneously (Cahyadinata et al. 2019; Hakim 2019).

(1) Absolute poverty which occurs in fishing communities is closely related to the poverty line of the area. For example, the poverty line of a fishing community in one village in Bengkulu Province, Indonesia, is IDR 369,367 per capita/month. The poverty line of fishing communities is often associated with an index of the depth and severity of poverty.

(2) The relative poverty that occurs in fishing communities can be identified if the fishing communities individually have been able to fulfill their basic needs (clothing, food, shelter, and other basic needs such as education, etc.), but still need to meet the welfare requirements of the surrounding fishing communities. Based on this concept, poverty can be seen in terms of the depth and severity index of poverty or in terms of social inequality. If the level of social inequality that occurs in the fishing community (i.e., inequality between well-off fishermen and small-scale fishermen is getting bigger), the larger the number who can be categorized as poor.

(3) Cultural poverty is a phenomenon that tends to occur as a result of the indifference of the small-scale fishing community to their condition (because they feel comfortable with their poverty).

Changing the helplessness or inadequacy of small-scale fishermen to a better condition is a hope and a coveted goal. Indicators of changes in welfare, especially for fishermen's communities, can be shown by improving the performance of these communities in the form of fish catch production, related to its role as a manager of marine natural resources or capture fisheries. Regionally, the quality of the performance of fishermen communities in producing capture fisheries can be reflected through the development of capture fisheries production in a given area (Merayo et al. 2018; Tamboto et al. 2018). Nationally, the performance of capture fisheries production is still not optimal, and this performance is still dominated by small-scale/traditional fishermen. This condition occurs because a large number of these communities are still dominated by small-scale fishermen (traditional fishermen). This under-optimal performance of capture fisheries from marine natural resource occurs in almost every province. Performance benchmarking between fishermen communities from one region (province) to another can be illustrated through comparisons between regions (provinces) that have not been successful and regions (provinces) that have been successful, so that the two regions can be compared in terms of strengths and 
weaknesses. Contextually, regions/provinces that have not been successful are shown by the example of Bengkulu province, while areas that have been successful are shown by the example of East Java province. A detailed illustration of the comparison of the development of capture fisheries production between Bengkulu and East Java provinces can be seen in Table 1.

Table 1. Development of capture fisheries production performance from Bengkulu and East Java Provinces, Indonesia, 2014-2019 (in tons).

\begin{tabular}{cccc}
\hline No. & Year & $\begin{array}{c}\text { Production from } \\
\text { Bengkulu Province }\end{array}$ & $\begin{array}{c}\text { Production from East Java } \\
\text { Province }\end{array}$ \\
\hline 1 & 2014 & 60,705 & 385,878 \\
2 & 2015 & 62,291 & 402,569 \\
3 & 2016 & 62,426 & 390,271 \\
4 & 2017 & 65,755 & 551,925 \\
5 & 2018 & 67,299 & 467,960 \\
6 & 2019 & 70,829 & 680,221 \\
\hline
\end{tabular}

Sources: Central Bureau of Statistics, Indonesia, 2020.

Table 1 shows that the average amount of capture fisheries production from East Java province is far above Bengkulu province, which indirectly reflects differences in performance seen from the aspect of marine natural resource management. Geographically, these two provinces should have similar performance, because they both have the same endowment factor, where they face the Indian Ocean directly. Therefore, extreme differences in performance between these two provinces should not be allowed to occur. However, the facts show that the two provinces have striking differences in performance from one another. Differences in the performance of fishing communities between Bengkulu and East Java provinces are also reflected in differences in the poverty conditions of fishing communities and differences in the institutional capital system that occur within them. $\mathrm{Ob}$ servation results show that the welfare level of small-scale fishing communities in Bengkulu is much lower than that of small-scale/traditional fishing communities in East Java. Several studies show that the various differences in the performance of fishing communities are caused by differences in various influencing variables such as the quality of small-scale fishermen's capital capabilities, the quality of fishing facilities and infrastructure, and the quality of social capital (cooperation, collaboration, mutual trust, the strength of work motivation, etc.) (López de la Lama et al. 2018).

Generally, capital assistance coming from capital providers (usually by groups of welloff fishermen) is a cooperative system in the form of capital assistance that occurs in coastal communities, especially to increase the capital capacity of small-scale fishermen. Normatively, this cooperation is one aspect of social capital that should be mutually beneficial for the parties involved (i.e., fishing communities). This normative condition is supported by several studies which show that empirically the essence of this cooperative characteristic has turned into a detrimental capital assistance system, even similar to the practice of loan sharks (a capital cooperation system that deviates from the principle of social capital). The results of the study of Kamarni et al. (2019) show that the institutional aspect in the form of cooperation has an important or strong influence in the elimination of poverty-trapping practices. One of the approaches introduced is a system of providing capital assistance in the form of microfinance (Musari and Arodha 2017). Social capital is a concept of social relations that emphasizes the importance of cooperative relationships between members in groups and relationships between groups in a community. This concept is different from the concept of human capital, which places more emphasis on individual dimensions such as strength and expertise possessed individually. Empowerment of social capital can have an impact on the success of fishermen, such as changing socio-economic conditions for the better or escaping poverty (Bakker et al. 2019; Sinarwati et al. 2019). 
Capital assistance to fishing communities is also carried out by the government (state), but its form is not similar to that provided by private capital assistance providers (generally carried out/played by well-off fishermen). Capital assistance from the government (represented by the Department of Marine Affairs and Fisheries), is generally physical in nature, such as assistance for fishing fleets/boats, fishing equipment, and so on (Van Hoof et al. 2020). The duration of the program is not a routine one administratively (usually based on the program that has been made before/prearranged). On the other hand, small-scale fishing communities (traditional fishermen) need more capital assistance in the form of cash funds, which are used for daily working capital (for fishing activities) and other needs such as the educational needs of their children (Liu et al. 2021). This disparity in roles between the government (state) and private financiers (well-off fishermen) is allegedly the cause of the practice of capital assistance providers from the private sector (many are played by well-off fishermen), which is "detrimental".

Based on the source of capital, the working capital used by small-scale fishermen mostly comes from individuals, groups, or comes from an institution (e.g., fishermen/fishery cooperative institutions). Cooperative institutions are institutions that actually have a very important role and function as a provider of working capital for daily activities in carrying out fishing activities (McKillop et al. 2020). The fishing community's need for working capital is motivated by two conflicting conditions: on the one hand, fishermen have a strong desire to improve their fishing performance, but on the other hand show powerlessness in accessing capital ownership, which is needed by fishermen in order to optimize the performance of capture fisheries from natural resources exploitation. Additionally, small-scale (traditional) fishing communities are faced with a capital assistance system controlled by a group of capital providers originating from well-off fishermen, which tends to be detrimental to small-scale fishermen. The capital assistance system that occurs in the fishing community is clearly inappropriate or deviates from the values of social capital.

Social capital is an aspect contained in the social development of society based on non-individual groups as well as the concept of human capital. Two important elements of social capital are cooperation and trust. Viewed from the aspect of cooperation, social capital can be defined as an attitude that involves networks, social norms and beliefs that encourage social collaboration or cooperation for the common good. Trust is an attitude of interdependence based on an attitude of honesty, a sense of responsibility, or an attitude of togetherness that is always expected (Siegelman et al. 2019). In the context of fishing communities, social capital behavior is reflected by the attitude of cooperation and mutual trust between members of the group. In the case of cooperation in the form of capital assistance between the lenders and the fishing community, especially small fishermen, the phenomenon or mechanism should not be detrimental (Malherbe et al. 2020).

The linkage of helplessness (poverty) of small fishermen, which is shown by the low performance of capture fisheries production, has theoretically been strengthened by the theory or model of "Logistic Growth" of marine natural resources (see Figure 1). This theory/model explains that the results of marine natural resource management are actually influenced by the ability and efforts of fishermen to exploit the potential of their marine natural resources. The result of the exploitation of capture fisheries natural resources $(\mathrm{h})$ is assumed to be a function of effort (E) and the stock of captured fishery resources (x), so that it can be formulated into a causal relationship: $h=f(x, E)$. Effort $(E)$ is an index of various inputs such as fishermen, fishing vessels, fishing gear, and so on. Explicitly, the production function can be changed to: $h=q \cdot E$, where $q$ is the ability coefficient to catch or is the proportion of fish stocks that can be caught by one unit of effort. This causal relationship can be explained by the fact that the optimization of the performance of fisheries natural resource management results depends on the level of fishermen's fishing ability (as a function of the working capital and managerial abilities) of fishermen. The higher quality of the level of catching capacity and effort (including fishing facilities and infrastructure), the higher the performance in terms of fish catches (Akpalu and Eggert 2021). 


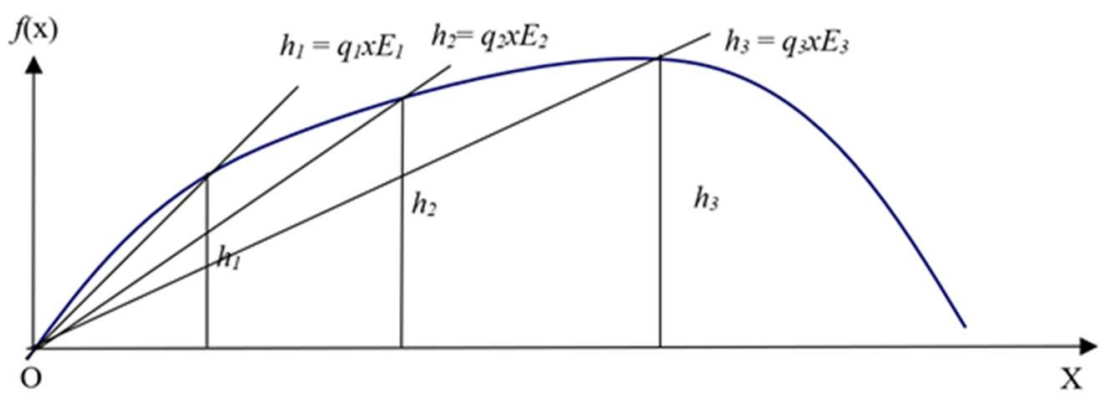

Figure 1. Gordon-Schaefer model of capture fisheries natural resources.

Figure 1 shows that the change in position of E (Effort) from E1 to E2 and E3 means that the performance of captured fisheries production (h) changes according to the change in the amount of E. The performance of capture fisheries production (h1) is lower than $\mathrm{h} 2$ and the performance of $\mathrm{h} 3$ production turns out to be higher when compared to h2. In the context of helplessness or poverty conditions that occur in fishing communities (small-scale fishermen), E (effort of small-scale fishermen) is in the lowest position, i.e., E1, so it is natural that the performance of captured fisheries of natural resource production is relatively low. If E (Effort) is increased to E2, then the yield performance (h) of fisheries' natural resources will increase (small-scale fishermen will be more empowered). The case of capture fisheries production (especially for "Cakalang or skipjack fish") in Indonesia in 2010-2016 shows a condition of "overfishing", even though it is still in the MEY (Maximum Economic Yield) position. MEY (Maximum Economic Yield) is a position where capture fisheries production is at a maximum position (h3) (Anna 2018; Yoshioka et al. 2019; Wijayanto et al. 2020). As a result of the moratorium policy on the use of "effort" in the form of Cantrang in South Sulawesi, the policy has a significant impact on reducing operational costs or increasing total revenue from fishermen.

A thesis from Garrett Hardin entitled "tragedy of the commons" explains that in the management of common natural resources such as marine natural resources (capture fisheries) which are "open access", it is impossible to take collective action to achieve results that are of mutual benefit through group arrangement. If the group is unable to manage properly or without good control (without applying the correct managerial principles), it will result in a tragic loss (tragedy). This concept indicates the importance of professional management capabilities, to be able to produce high production performance and be able to provide great benefits for improving the welfare (reducing poverty levels) of the surrounding communities. The inability to optimize management in the exploitation of common natural resources is not only caused by individual inability but also due to social inability (as a group). The social inability can be exemplified by the inability to build mutually beneficial cooperation, which is reflected in the capital assistance system between the capital provider and the recipient of capital assistance, the weak role of the capture fisheries auction market, and weak aspects of social capital (individual and group/community) (Rose 2020).

The problems that arise from the contradiction between empirical conditions (dasSein) and normative conditions (das-Solen) that have been described previously present three important questions (as a form and reflection of research gaps), as follows: (1) What is the extent to which the capital assistance system from capital providers (mostly played by well-off fishermen) deviates from the principle of social capital (does not reflect cooperation in the form of mutually beneficial capital assistance)? (2) Why are smallscale fishermen easily caught in the trap of this detrimental capital assistance system? (3) How can the performance of fishermen be built through the transformation of the capital assistance system that previously deviated (harms) to be in accordance with the principle of social capital (mutual benefit)? The answers to these three questions are emphasized by the three main objectives of this study, namely: (a) revealing the practice of capital assistance management systems in coastal communities that are indicated to 
deviate from the principles of social capital, (b) revealing the factors that cause small-scale fishermen to be easily trapped by detrimental capital assistance, and (c) building a model as a series of solutions in improving the performance of fishermen, especially small-scale fishermen, through the development of an integrated capital system (involving all relevant stakeholders). The research hypothesis that can be put forward is "the level of deviation from the principles of social capital (cooperation and togetherness/mutual trust) in the implementation of the capital assistance system (working capital) that occurs in fishing communities, will determine/affect the level of workability of fishermen in exploiting natural resources of capture fisheries and the high and low performance of fishermen".

\section{Methodology}

\subsection{Population and Samples}

This research was conducted in Indonesia, focused on coastal regions in two provinces which have different characteristics or performance. Those two are Bengkulu Province (Bengkulu City serves as a sample region, to represent low performance) and East Java Province (Malang Regency serves as a sample area, to represent high performance). Based on the target population in coastal communities, the research sample consisted of respondents and key informants representing small fishermen/traditional fishermen figures, providers of capital assistance, and policymakers from relevant agencies. Sampling was performed using a purposive method to obtain data (information) in accordance with the purpose of the research. Additionally, it serves to guarantee the level of accuracy of the data.

\subsection{Standardization of Research Instruments}

The response from respondents representing small fishermen/traditional fishermen figures, providers of capital assistance, and policymakers from relevant agencies are expected to meet the standards required in research. Therefore, the following steps were carried out: (1) respondents representing all elements of the selected stakeholders and samples were selected based on simple random sampling and purposive sampling methods, (2) determination of sample characteristics was based on theoretical studies and several previous studies, (3) validity tests were conducted by "bivariate person" to measure whether the list of questions given to the respondents was valid, (4) reliability tests were conducted by "alpha cronbach" to measure the level of reliability/level of confidence in the measuring instrument, and (5) preliminary research was conducted, in order to make revisions when errors both in the research sample and research instrument were found during "team discussion".

\subsection{Research Variables, Data, and Analysis Methods}

The variables for the research are six factors (latent variables), consisting of the performance of fishermen (small fishermen) factor (Z), the effort factor (X1), the function of the fish auction market factor $(X 2)$, the quality of social capital factor (cooperation and mutual trust in the fishing community) (X3), the quality of the fishing community's ability factor (working capital ability and managerial knowledge) (X4), and the role of related government agencies factor (Department of Marine and Fisheries Affairs) (X5). The latent variables were analyzed by the discriminant analysis method. The performance of fishermen factor is the one that shows the productivity of fishermen (small fishermen) with indicators of the amount of fish catches as a form of the exploitation of marine natural resources. The effort factor is a factor supporting the ability of fishermen to catch with indicators of fishing facilities and infrastructure, such as the quality and quantity of fishing vessels, quality of fishing gear, and quality of market facilities to sell catching. The function of the fish auction market factor, which is classified as infrastructure for selling the fish, is reflected by how good the contribution of the fish auction market is in improving the performance of fishermen. The quality of the social capital factor is related to the principles used as a basis for determining whether the capital assistance system in fishing 
communities is a mutually beneficial cooperation (in accordance with the principles of social capital) or detrimental one to fishermen (deviating from the principles of social capital). Additionally, it is related to the presence or absence of mutual trust. The quality of the fishing community's ability factor, as a combination of working capital and managerial knowledge abilities, is a condition which represents the ability of fishermen in accessing working capital in the capital assistance system, both for daily fishing activities and for certain loans. This factor is a function of the quality of the implementation of the capital assistance system and managerial ability and knowledge in fishing communities. The role of related government agencies (Department of Marine and Fisheries Affairs) is in solving the problems of fishing communities in their working areas through empowering, counseling, mentoring, and education (Anna 2018; Van Hoof et al. 2020).

Seven factors (latent variables) analyzed by the SEM (SmartPLS) Analysis Method are (1) fisherman's performance (A), a factor that indicates the productivity of fishermen in the form of amounts of fish caught (a marine natural resource), (2) fishermen's workability (B), the ability of fishermen seen from the range of work (distance traveled by fishermen from the beach to the work/catching area), (3) fishermen's work motivation (C), the hard work (work ethic) of fishermen as measured by the indicator of the time/duration of fishermen carrying out their working activities, (4) fishermen's working capital (D), a condition of the ability of fishermen in accessing working capital of capital assistance systems, both for daily fishing activities and for certain loans, as a result of the implementation of the capital assistance system in fishing communities, (5) fisherman's formal education (E), the level of education of fishermen, (6) fishermen's social capital, defined as cooperative attitudes between groups in fishing communities $(\mathrm{F})$, a factor related to the principles to measure the type of cooperation in capital assistance systems, and whether it led to mutual benefit (in accordance with the principles of social capital) or detriment (deviating from the principles of social capital), and (7) fishermen's social capital in the form of togetherness (a form of mutual trust) $(G)$, a factor related to the principles of mutual trust in which to determine whether the capital assistance system is in accordance with or deviates from the principle of mutual trust/togetherness.

The data collected were primary data together with secondary data to serve as supporting data. The collection of primary data was carried out through observation and in-depth interviews, while secondary data were collected using the documentation method. After collection, the primary data were then analyzed using two data analysis methods, i.e., the quantitative data analysis method and qualitative data analysis method, which is in category of descriptive methods. For quantitative data analysis, the analytical method was conducted by discriminant and SEM (SmartPLS) analysis methods. The discriminant analysis method was used to analyze five factors (latent variables) of $\mathrm{X} 1, \mathrm{X} 2, \mathrm{X} 3, \mathrm{X} 4$, and $\mathrm{X} 5$ to determine the performance level of fishermen in optimizing the exploration of the natural resources (catching of fisheries/marine resources) in Bengkulu Province, while the SEM (SmartPLS) analysis method was employed to analyze seven factors (latent variables) of A, B, C, D, E, F and G to determine the performance level of fishermen in optimizing the natural resources of capture fisheries/marine resources in East Java province.

\section{Results and Discussion}

\subsection{The Quantitative Analysis}

3.1.1. Performance Determinant of Fishermen Communities and Their Relationship with the Capital Assistance System in Bengkulu Province, Indonesia

Based on the discriminant analysis method for samples in Bengkulu Province, Indonesia), the obtained five factors that significantly influence or differentiate the performance of fishermen in optimizing marine natural resources $(Z)$ are as follows: the effort factor (X1) (4.824), the function of the fish auction market factor (X2) (1.098), the quality of social capital factor (cooperation and mutual trust in the fishing community) (X3) (0.919), the quality of the fishing community's ability factor (working capital and managerial knowledge) (X4) (1.370), and the role of related government agencies factor (Department of 
Marine and Fisheries Affairs) (X5) (2.400). With an error rate $(\alpha)=5 \%$, a mathematical model (unstandardized model) of the causal relationship of fishermen's performance in optimizing marine natural resources is written as follows:

$$
Z=-24.529+4.824 X 1+1.098 X 2+0.919 X 3+1.370 X 4+2.400 X 5 .
$$

From five determinant factors in the model, the one which is considered as an important and strategic discriminator in improving the performance of fishermen $(Z)$ is the quality of the social capital factor (cooperation and mutual trust in fishermen communities) (X3). This relationship means that through the right use of social capital, it is expected that a capital assistance system which was previously detrimental (binding) can be transformed into a mutually beneficial (non-binding) one. This process leads to the empowerment of fishermen in optimizing the management of the exploitation of marine natural resources. This result is corroborated by works in other regions in Indonesia (Kupang Regency), which also show the similar result in which the empowerment of small fishermen is very important in accessing their natural marine resources. Additionally, it can be noted that the difference in the level of empowerment between small-scale fishermen and well-off fishermen is reflected in the differences in fishing methods and efforts, resulting in a very striking difference in catch performance between the two groups of fishermen, i.e., the small-scale fishermen group and the well-off fisherman group. This condition is in accordance with the results of previous studies which show that seven important factors in the capture fisheries system are economic, social, government policies, culture, environmental, science, and technology factors; all factors work in an integrated manner and support each other.

3.1.2. Performance Determinants of Fishermen Communities and Its Relationship with the Capital Assistance System in East Java Province, Indonesia

Research was conducted in the coastal area of East Java Province (Indonesia). The results show a causal relationship where structurally, analyzed through the SEM/SmartPLS method, the performance of fishing communities is significantly determined/influenced by six factors, either directly or indirectly. The three structural mathematical models are:

(1) Model 1: Fishermen's performance $=0.509$ Fishermen's work ability +0.309 Fishermen's work motivation;

(2) Model 2: Fishermen's working ability $=0.679$ Working capital for fishing activities + 0.090 Fishermen's formal education; and

(3) Model 3: Fishermen's work motivation $=0.371$ Fishermen's social capital in the form of cooperation inter groups +0.231 Fishermen's social capital in the form of togetherness in groups.

Graphically, the causality relationship of these three mathematical models is shown in Figure 2.

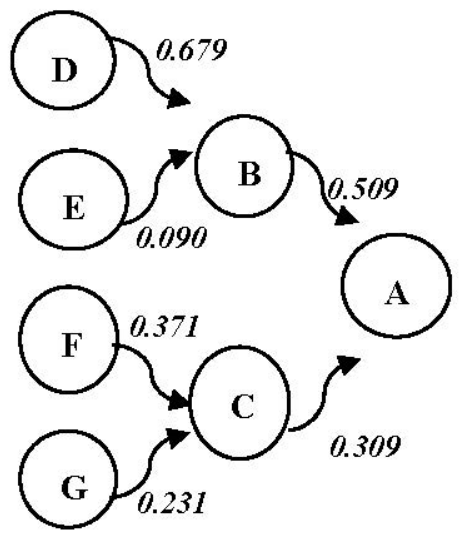

$$
\begin{aligned}
& \text { Note: } \\
& \mathbf{A}=\text { Fishermen's performance } \\
& \mathbf{B}=\text { Fishermen's worling ability } \\
& \mathbf{C}=\text { Fishermen's work motivation } \\
& \mathbf{D}=\text { Working capital for fishing activities } \\
& \mathbf{E}=\text { Fi sherman formal education }
\end{aligned}
$$

Figure 2. The PLS-SEM model: determinant factors of fishermen's performance. 
Figure 2 shows a model/structural equation of the factors that influence the performance level of fishermen: (1) Model 1 shows that the performance of fishermen (A) as represented by the volume of fish caught is determined (influenced) directly by the working ability of fishermen (B) (with a path coefficient/influence coefficient of 0.509) and fishermen's work motivation (C) (with a path coefficient/influence coefficient of 0.309); (2) Model 2 shows that the working ability of fishermen (B) is determined/influenced directly by fishermen's working capital (D) (with a path coefficient/influence coefficient of 0.679) and fishermen's formal education (E) (with a path coefficient/influence coefficient of 0.090); (3) Model 3 shows that fishermen's work motivation (C) is determined/influenced directly by fishermen's social capital in the form of the cooperation of inter groups of fishermen (F) (with a path coefficient/influence coefficient of 0.371) and fishermen's social capital in the form of mutual trust/togetherness in groups $(G)$ (with a path coefficient/influence coefficient of 0.231 ).

The analysis and elaboration of the research results show that the direct positive effect of the working ability of fishermen (B) on the performance of fishermen (A) is quite significant (indicated by the path coefficient/influence coefficient of 0.509) which indicates that the working ability of fishermen has implications for the needs for additional working capital in order to indirectly increase the performance of fishermen. This condition is confirmed by the coefficient of the effect of working capital (D) on the work ability of fishermen (B), which is significant and relatively high, as shown by the coefficient of influence of 0.679 . The significance of this influence shows the importance or urgency of working capital as a basic need for fishermen, especially for small-scale fishermen. The test results of the SEM/SmartPLS analysis method have indirectly answered (supported) the proposed hypothesis of "the level of deviation from the principles of social capital (cooperation and togetherness/mutual trust) in the implementation of the capital assistance system (working capital) in fishing communities, will determine/influence the level of work ability of fishermen in exploiting natural resources in form of capture fisheries and the performance level of fishermen". The impact that occurs as a result of this condition is new providers of capital assistance increasingly emerging, which generally come from well-off fishermen. The continuous need for working capital has resulted in a change in the orientation of the financiers (well-off fishermen) from helping (mutually benefit) to burdensome (detrimental) for small-scale/traditional fishermen.

\subsubsection{Two Novelties of Research}

A very important "novelty" of this research is the impact of the practice of the "detrimental" capital assistance system from well-off fishermen to small-scale fishermen/traditional fishermen. This detrimental nature of capital assistance (loans) makes small-scale fishermen very dependent on well-off fishermen (making a form of dependence), which normatively (based on the principle of social capital) should be in the form of "altruism" as an actualization of the forms of mutual trust (McKillop et al. 2020). The practice of the "detrimental" capital assistance system, which is a deviation on the principles of social capital, in addition to causing the weak working capital capabilities of fishermen, also has a subsequent impact on the weakening of the ability to optimize the exploitation of marine natural resources. The importance of the principles of social capital can be explained as follows. Theoretically, two important elements of social capital that are "inherent" in fishing communities are elements/factors of cooperation between groups of fishermen and elements/factors of togetherness of members in groups. These two elements/factors are considered to have an indirect effect on improving the performance of fishermen by increasing fishermen's work motivation (Sinarwati et al. 2019). This relationship can be explained by the fact that increasing social capital (cooperation and mutual trust/togetherness) will increase one's work motivation. So, it can be concluded that building/strengthening the attitude of cooperation and mutual trust/togetherness in the fishing community, by seriously adhering to the principles of social capital, will be able to significantly increase the work motivation of fishermen. Collaborating with the working 
ability of fishermen will simultaneously be able to significantly improve the performance of fishermen, which in turn will optimally improve the management of natural resources for capture/marine fisheries.

The working ability of fishermen is also determined by the level of formal education of fishermen. This condition shows the importance of the role of education in increasing the ability to accept knowledge, changes, and innovations available to the community. With the wider knowledge of fishermen, it will indirectly improve the performance of fishermen. Therefore, the role of the Government (state) in eradicating illiteracy is a necessity through suitable programs. The programs offered by the Government are generally carried out through non-formal education and training. The indirect effect of educational factors on fisherman's performance through increasing fishermen's working ability can be considered as another important "novelty" of this research. The reasons that can be put forward are (1) in previous studies, formal education factors are generally not included in the research model, even though it is very useful in explicitly explaining the causal relationship that occurs in the process of improving the performance of fishermen; and (2) the formal education factor is often regarded as a moderate variable which is only reinforcing and is even considered to not have an effect on increasing the working ability of fishermen, even though the formal education variable is proven to have a direct effect on the working ability of fishermen, as shown in the structural relationship in Figure 2 (Liu et al. 2021).

\subsection{The Qualitative Analysis}

3.2.1. The Capital Assistance System's Implementation in Coastal Areas

a. The Implementation of Detrimental Capital Assistance System

The implementation of the capital assistance system in fishing communities refers to capital assistance used for the purpose of increasing working capital needs. From the results of the interview, the capital assistance is "a loan". There are two consequences imposed by lenders (well-off fishermen) to small-scale fishermen: (1) consequences in the form of "bindings" which bind small-scale fishermen to deposit or sell their catches to lenders (well-off fishermen) and (2) consequences in the form of debt-receivable bonds, usually in unwritten contracts/only based on the conventions of both parties, in which receivables that have been invested to small-scale fishermen are not allowed to be repaid or given back even though small-scale fishermen as recipients of a loan already have sufficient funds to repay the debt. This form of capital assistance clearly does not reflect cooperation in accordance with the principles of social capital. The results of observations and interviews with small fishermen show that this "unopened" marketing mechanism, mainly because it is not carried out through an auction process in the fish market, has become a pattern in the price-fixing process that is unfair and detrimental to small-scale fishermen. This situation has happened because of no element of mutual trust, and the low level of cooperation or attitudes of helping others (altruism).

b. The Impact of Detrimental Capital Assistance Systems in Coastal Communities

The powerlessness of small-scale fishermen means they need an injection of capital in meeting their working capital needs, which are always far from sufficient. Therefore, the offering of capital loan from the lenders (well-off fisherman) is considered as a highly expected "sustenance", even though it has various "detrimental/binding" conditions and has detrimental or burdensome effects on small-scale fishermen. The powerlessness of small-scale fishermen makes them unable to optimize the "gift" in the form of marine natural resources. One theory of natural resources shows that capture fisheries are a variant of marine natural resources. As implied in the Gordon-Schaefer Model (see Figure 1), the optimization of marine natural resource management has a positive (linear) correlation with the ability and efforts of fishermen to utilize the potential of marine natural resources. Ability or empowerment includes the ability of working capital and knowledge of fishermen in managerial aspects. Efforts related to fishing facilities and infrastructures such as the quality and quantity of fishing vessels, quality of fishing gear, and other qualities. 
Several previous studies have shown that improving the quality of efforts in the form of fishing facilities will increase the ability to optimize the management of natural resources for capture fisheries (Rivai et al. 2017; Yoshioka et al. 2019; Sabihaini et al. 2018).

\subsubsection{Setting of the Capital Assistance System Transformation Model: A Solution for} Improving Fishermen's Performance

Through benchmarking studies between successful regions (province) and unsuccessful ones in their capture fisheries performance in Indonesia, and based on the results of interviews and focus group discussions, finally, a qualitative model (in the form of diagrams) is created to provide a "solution" to reduce (eliminate) the practice of the "detrimental" capital assistance system in fishing communities, with the following steps:

(1) The detrimental (binding) capital assistance system has an impact on the undeveloped performance of fishermen. This is caused by the capital assistance being unable to have an effective enough impact on increasing working capital, even though from hypothesis testing it was proven that the working ability of fishermen has a positive direct influence on the performance of fishermen, which is quite strong as shown in the results of the analysis using the SEM/SmartPLs method. It gives a path coefficient/influence coefficient of 0.509 . The influence of working capital assistance on the working ability of fishermen is also quite strong, as shown in the results of the analysis using the SEM/SmartPLs method, which gives a path coefficient/influence coefficient of 0.679 . The ineffectiveness of the effect of working capital assistance on increasing the working ability of fishermen is caused by a detrimental binding factor, i.e., the additional prerequisites that are burdensome and covert (not clearly visible) to small-scale fishermen as recipients of the loan. The purpose of this burdensome condition is that existing loans (receivables) given to small-scale fishermen (loan recipients) intentionally cannot easily be returned, with the aim of being used as "binders", which implicitly makes small-scale fishermen become dependent capital recipients to the lenders (well-off fisherman) (Nissa et al. 2019).

(2) This form of binding or dependence is a form of "an obligation", in which fish catches from small-scale fishermen (traditional fishermen) must be deposited/sold/marketed to lenders (well-off fishermen). This closed marketing mechanism is one of the factors causing the non-functioning of the available fish auction market (a facility that is highly expected to become a fish marketing center through an open auction or marketing process).

(3) One of obstacles in the form of the increasing number of providers of detrimental capital assistance is the weak role of cooperative institutions, which should have a very important and strategic role, especially as a "safety valve" in providing funds/capital for fishing communities.

(4) A comprehensive solution that can be considered appropriate and urgent is to implement "empowerment efforts in the aspect of social capital", by focusing on aspects of cooperation and mutual trust. The main targets include small-scale/traditional fishing communities, well-off fishing communities, providers of private capital assistance, managers of cooperative institutions, managers of the fish auction market, the Department of Marine Affairs and Fisheries, and higher education institutions.

(5) The empowerment process in the aspect of social capital is intended to (1) raise the spirit of "altruism" (willingness to help others sincerely) from the lenders (generally from well-off fishermen) to small-scale fishermen, and (2) bring up an attitude in accordance with the principles of social capital (cooperation and mutual trust/togetherness) for stakeholders related to efforts in optimizing the performance of fishing communities.

(6) Graphically, the integrated model relates to the transformation (improvement) of the capital assistance system for fishing communities from detrimental to mutually beneficial, which is carried out through a process of "empowerment of social capital aspect" (cooperation and mutual trust/togetherness), which is based on the results 
of quantitative analysis (discriminant and SEM/SmartPLs methods) and qualitative analysis. The integrated model can be explained in detail in Figure 3.

Figure 3 shows the change (improvement) in performance from FP I (Performance I) to FP II (Performance II) as a result of the transformation of the "level of compliance" to the principles of social capital. Another effect also occurs on the productivity of fishermen, as shown by the transformation of MP I (marginal product/productivity of fishermen), which was originally MP I $=0$ when FP I was maximum. After the fisherman's performance increased (from FP I to FP II), productivity (MP) rose (increased) sharply to MP II (MP II $>>$ ). As confirmed by Yamazaki et al. (2018), improving the quality of social capital will have an impact on increasing the productivity of fishermen in managing marine natural resources.

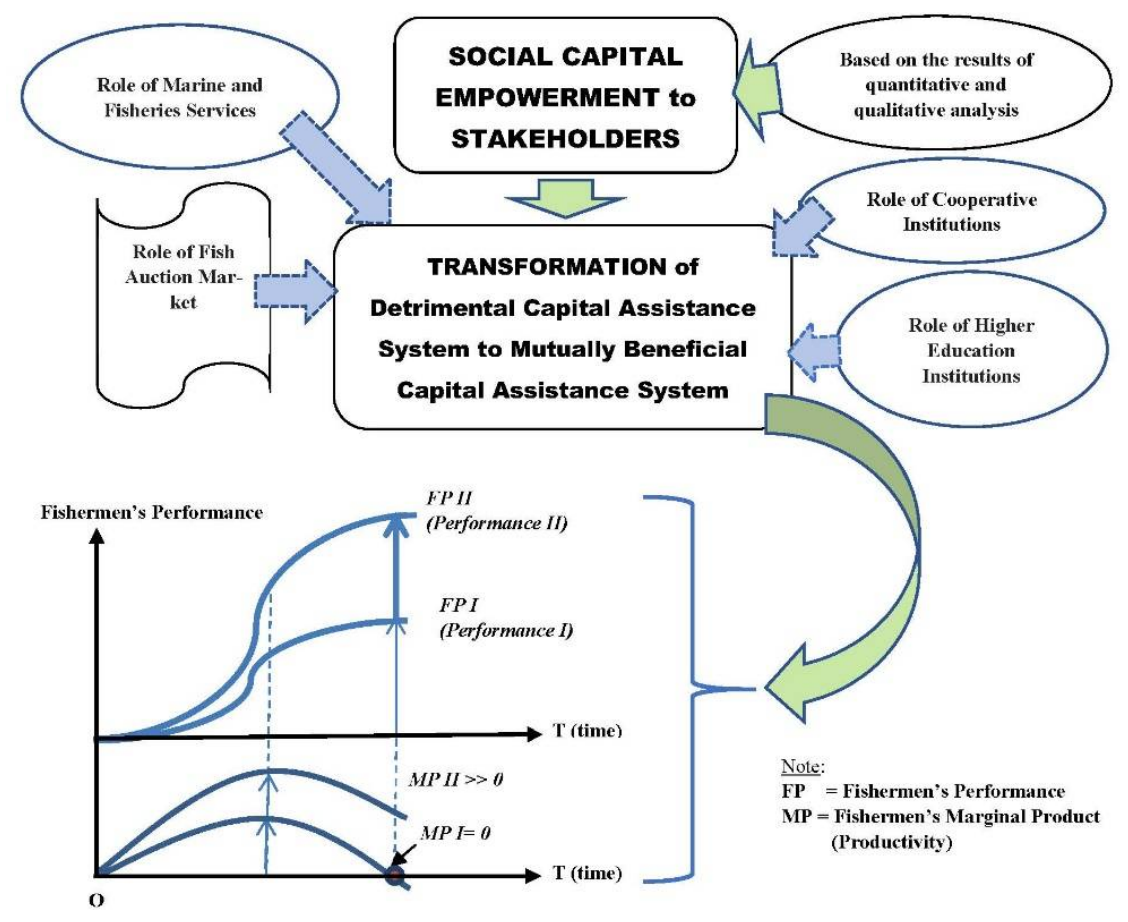

Figure 3. The integrated empowerment model of capital assistance system transformation: a comprehensive solution for improving fishermen's performance.

\section{Conclusions}

From the discussion of the empirical findings together with the elaboration of the findings of previous research conducted through quantitative and qualitative approaches, and referring to the three research objectives, three important conclusions can be drawn as follows:

(1) The cooperation in the form of capital assistance between capital providers (well-off fishermen) and recipients of capital assistance (small-scale fishermen/traditional fishermen) is proven to be a deviation from the principles of social capital (tends to be binding, detrimental, and unfair), and does not encourage a performance improvement in small-scale fisherman/traditional fisherman.

(2) There are five factors that cause deviations in the capital assistance system, including (a) the lack of "altruism cooperation" between well-off fishermen (providers of capital assistance) and small-scale fishermen or traditional fishermen, (b) mutual trust/togetherness in fishing communities as an important element of the principles of social capital is not developed, (c) the condition of the powerlessness of the fishing community, especially small-scale fishermen/traditional fishermen who need funds for working capital, (d) supervision and control from the government, especially from the Fisheries and Marine Affair Department is not effective, and (e) the role of 
cooperative institutions (fishery cooperation) especially in the aspect of providing funds/loan capital is still weak.

(3) The integrated empowerment model is considered capable of providing a comprehensive solution, where the mechanism is carried out through a process of empowering related stakeholders to improve the performance of fishing communities. Empowerment is emphasized on the principles of social capital (aspects of cooperation and mutual trust/togetherness), which are considered capable of transforming a detrimental capital assistance system into a mutually beneficial capital assistance system.

Author Contributions: Conceptualization, M.R. and A.I.; methodology, M.R.; software, A.I.; validation, M.R. and A.I.; formal analysis, M.R. and A.I.; investigation, M.R. and A.I.; writing-original draft preparation, M.R.; writing-review and editing, A.I.; visualization, A.I.; supervision, M.R. All authors have read and agreed to the published version of the manuscript.

Funding: This research received no external funding.

Institutional Review Board Statement: Not applicable.

Informed Consent Statement: Not applicable.

Data Availability Statement: Due to ethical and privacy concerns, supporting data are not publicly available but can be made available upon request, under a strict privacy protocol.

Acknowledgments: This article was written based on the results of a study conducted in two provinces in Indonesia (East Java and Bengkulu Provinces). The highest appreciation is conveyed to the relevant agencies, namely the Department of Marine Affairs and Fisheries of the Provinces of Bengkulu and East Java, Indonesia, and the Central Bureau of Statistics, all of which have supported the implementation of the study and supported the secondary data required for data analysis. We extend our deepest gratitude to all respondents who were willing to provide detailed information.

Conflicts of Interest: The authors declare no conflict of interest.

\section{References}

Akpalu, Wisdom, and Håkan Eggert. 2021. The economic, social and ecological performance of the industrial trawl fishery in Ghana: Application of the FPIs. Marine Policy 125: 104241. [CrossRef]

Amir Zal, Wan Ahmad, Nur Hanan Abdul Rahman, Tengku Fauzan Tengku Anuar, Hafizi Mat Salleh, and Siti Asma Md Rasdi. 2020. An innovation in poverty measurement based on community capital: A case study of young fishermen in Malaysia. Journal of Poverty 24: 543-67. [CrossRef]

Anna, Zuzy. 2018. An analysis of capture fisheries resource depletion in Cirata reservoir, West Java, Indonesia. Biodiversitas 19: 927-35. [CrossRef]

Anna, Zuzy, Arief A. Yusuf, Armida S. Alisjahbana, and Aisyah A. Ghina. 2019. Are fishermen happier? Evidence from a large-scale subjective well-being survey in a lower-middle-income country. Marine Policy 106: 103559. [CrossRef]

Azis, Ferawati, Rabihatun Idris, and Andi Agustang. 2017. Involution fisheries: Post-study model of national program in integrated movement at community fishermen's village development arungkeke, Jeneponto. Mediterranean Journal of Social Sciences 8: 441-41. [CrossRef]

Bakker, Yanick W., Jessica de Koning, and Jan van Tatenhove. 2019. Resilience and social capital: The engagement of fisheries communities in marine spatial planning. Marine Policy 99: 132-39. [CrossRef]

Cahyadinata, Indra, Achmad Fahrudin, and Rahmat Kurnia. 2019. Food security and multidimensional poverty of mud crab fishermen household in small and outer islands of indonesia. Case study: Enggano island, Bengkulu province. Aquaculture, Aquarium, Conservation E Legislation 12: 1196-207.

Hakim, Maksud. 2019. Fatalism and poverty in fishing communities. Society 7: 150-58. [CrossRef]

Kamarni, Neng, Muslich Anshori, and Raditya Sukmana. 2019. Poverty alleviation through social capital in coastal areas: Pariaman Coastal Case. Journal of Innovation in Business and Economics 3: 1-10. [CrossRef]

Liu, Fengqin, Li Li, Yun Qian Zhang, Quang-Thanh Ngo, and Wasim Iqbal. 2021. Role of education in poverty reduction: Macroeconomic and social determinants form developing economies. Environmental Science and Pollution Research 28: 63163-77. [CrossRef]

López de la Lama, Rocío, Armando Valdés-Velasquez, Luis Huicho, Estefanía Morales, and María Rivera-Ch. 2018. Exploring the building blocks of social capital in the Sechura Bay (Peru): Insights from Peruvian scallop (Argopecten purpuratus) aquaculture. Ocean and Coastal Management 165: 235-43. [CrossRef]

Malherbe, Willem, Warwick Sauer, and Shankar Aswani. 2020. Social capital reduces vulnerability in rural coastal communities of Solomon Islands. Ocean and Coastal Management 191: 105186. [CrossRef] 
McKillop, Donal, Declan French, Barry Quinn, Anna L. Sobiech, and John O. S. Wilson. 2020. Cooperative financial institutions: A review of the literature. International Review of Financial Analysis 71: 101520. [CrossRef]

Merayo, Eugenia, Rasmus Nielsen, Ayoe Hoff, and Max Nielsen. 2018. Are individual transferable quotas an adequate solution to overfishing and overcapacity? Evidence from Danish fisheries. Marine Policy 87: 167-76. [CrossRef]

Musari, Khairunnisa, and Dianidza Arodha. 2017. Can islamic microfinance unleash the coastal community from the loan shark?: A case study of Indonesia. International Journal of Islamic Banking and Finance Research 1: 14-24. [CrossRef]

Nissa, Zulfa Nur Auliatun, Arya Hadi Dharmawan, and Saharuddin Saharuddin. 2019. Vulnerability analysis of small fishermen's household livelihoods in Tegal City. Komunitas: International Journal of Indonesian Society and Culture 11: 167-76. [CrossRef]

Rivai, Andi Alamsyah, Vincentius P. Siregar, Syamsul B. Agus, and Hiroki Yasuma. 2017. Potential fishing ground mapping based on gis hotspot model and time series analysis: A case study on lift net fisheries in seribu island. Jurnal Ilmu Dan Teknologi Kelautan Tropis 9: 337-56. [CrossRef]

Rose, Carol M. 2020. Thinking about the commons. International Journal of the Commons 14: 557-66. [CrossRef]

Sabihaini, Sabihaini, Awang Hendrianto Pratomo, Heru Cahya Rustamaji, and Sudaryatie Sudaryatie. 2018. Environmental factors affecting traditional fishermen in maintaining the resilience of marine areas in the context of Indonesian State Defense. Humanities and Social Sciences Reviews 6: 46-54. [CrossRef]

Siegelman, Ben, Nora Haenn, and Xavier Basurto. 2019. "Lies build trust": Social capital, masculinity, and community-based resource management in a Mexican fishery. World Development 123: 104601. [CrossRef]

Sinarwati, Ni Kadek, Budhi Made Kembar Sri, Utama Made Suyana, and Anak Agung Istri Ngurah Marhaeni. 2019. The role of social capital for the performance of msmes. Russian Journal of Agricultural and Socio-Economic Sciences 11: 147-53. [CrossRef]

Tamboto, Henry J. D., Allen A. C. Manongko, and James J. Manengkey. 2018. Poverty alleviation based on economic literacy and social capital in improving economic welfare in coastal communities North Minahasa Regency, North Sulawesi Provence, Indonesia. International Journal of Scientific Research and Management 6: 806-12. [CrossRef]

Van Hoof, L., N. A. Steins, S. Smith, and M. Kraan. 2020. Change as a permanent condition: A history of transition processes in Dutch North Sea fisheries. Marine Policy 122: 104245. [CrossRef]

Wantini, Santi Ayu, Atikah Nurhayati, BS Ibnu Bangkit, and Asep Agus Handaka. 2020. The role of fishermen's wives to increase the incomes of traditional fishermen households (A case study at Pangandaran Sub District, Pangandaran District, Indonesia). Asian Journal of Fisheries and Aquatic Research 7: 43-51. [CrossRef]

Wijayanto, Dian, Indradi Setiyanto, and Hendrik Anggi Setyawan. 2020. Bio-economic model of Danish seine and purse seine fisheries in Rembang Regency, Indonesia. Egyptian Journal of Aquatic Research 46: 63-70. [CrossRef]

Yamazaki, Satoshi, Budy P. Resosudarmo, Wardis Girsang, and Eriko Hoshino. 2018. Productivity, social capital and perceived environmental threats in small-island fisheries: Insights from Indonesia. Ecological Economics 152: 62-75. [CrossRef]

Yoshioka, Hidekazu, Yuta Yaegashi, Yumi Yoshioka, and Kentaro Tsugihashi. 2019. A short note on analysis and application of a stochastic open-ended logistic growth model. Letters in Biomathematics 6: 67-77. [CrossRef] 